\title{
Análise da Dissecação Horizontal e Vertical da Bacia Hidrográfica do Córrego Moeda, Três Lagoas/MS
}

Analysis of the Horizontal and Vertical Dissection of the Hydrographic Basin of the Stream Moeda, Três Lagoas/MS

Análisis de la Disección Horizontal y Vertical de la Cuenca Hidrográfica Arroyo Moeda, Três Lagoas/MS

Weslen Manari Gomes

Mestrando em Geografia, Universidade Federal do Mato Grosso do Sul, UFMS, Brasil weslenmanari@hotmail.com

\section{Angélica Estigarribia São Miguel} Graduada e mestre em Geografia pela Universidade Federal do Mato Grosso do Sul, UFMS, Brasil angelica.esm@hotmail.com

André Luiz Pinto Professor associado IV, Universidade Federal do Mato Grosso do Sul andre.pinto@ufms.br 


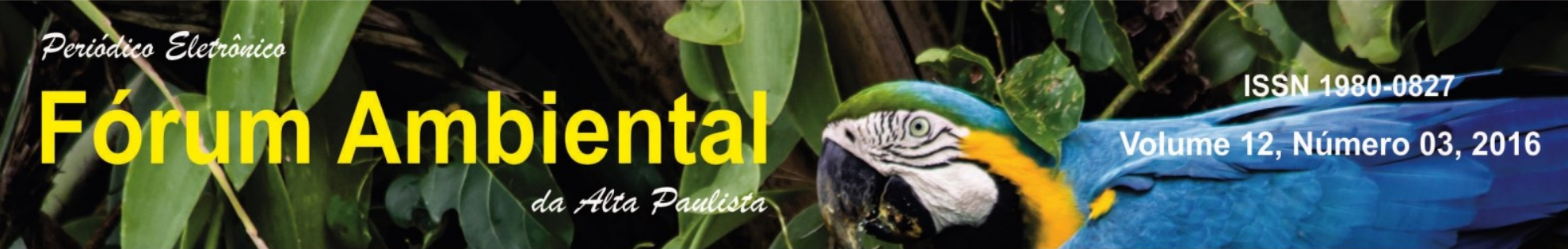

\section{INTRODUÇÃO}

O homem tem aumentado, cada vez mais, sua capacidade de alterar o meio em que vive. Isso se faz possível devido à evolução das técnicas e da necessidade de exploração dos recursos naturais. Muitas vezes essa exploração não tem ocorrido de forma planejada, podendo acarretar vários problemas ambientais, como por exemplo, erosões, assoreamento de cursos d'água entre outros.

Um dos principais problemas enfrentados na atualidade, quando se altera o equilíbrio natural de uma determinada área ou região, são os possíveis surgimento de processos erosivos. Para que esses processos sejam minimizados faz-se necessário o conhecimento, principalmente do relevo. Logo, o primeiro passo a ser tomado é a delimitação da área, no caso, de estudos.

A Política Nacional de Recursos Hídricos (PNRH), estabelecida pela lei no 9.433 de 8 de janeiro de 1997, mais conhecida como Lei das Águas, congrega princípios e normas que regem a gestão dos recursos hídricos no Brasil, aceitando, pois, a Bacia Hidrográfica como unidade de estudo e de planejamento.

Tendo em vista a possibilidade de análise dos diversos elementos e as interações existentes entre eles, Botelho; Silva (2007, p. 153) afirma que a bacia hidrográfica é "entendida como célula básica de análise ambiental. Sendo assim, a bacia hidrográfica permite reconhecer e avaliar seus diversos componentes e os processos de interação que nela ocorrem".

Logo, utilizou-se a Bacia Hidrográfica do Córrego Moeda (BHCM) para análise neste artigo, a qual possui área de $247,67 \mathrm{~km}^{2}$ e fica localizada ao sul da sede do município de Três Lagoas/MS, na margem direita do rio Paraná entre as coordenadas geográficas de $20^{\circ} 50^{\prime} 00^{\prime \prime} \mathrm{e}$ $21^{\circ} 01^{\prime} 10^{\prime \prime}$ de latitude $\mathrm{S}$ e $51^{\circ} 44^{\prime} 55^{\prime \prime}$ e $52^{\circ} 01^{\prime} 08^{\prime \prime}$ de longitude W. (Figura 1)

O objetivo da pesquisa é a análise da dissecação horizontal e da dissecação vertical da BHCM, para isso, faz-se necessário a elaboração de ambas as cartas, as quais foram elaboradas e analisadas com o auxílio do software Arcgis 10. Para a elaboração da carta de Dissecação Horizontal foi adotada a proposta de Spiridonov (1981), considerando as adaptações de Mendes (1993) e Mauro et al. (1991).

Pode-se dizer que a elaboração da carta de dissecação horizontal faz-se necessária quando o objetivo é a obtenção de dados com grande nível de detalhes "a fim de identificar cada setor da área estudada que apresenta maior concentração de cursos fluviais e/ou nascentes em posicionamento que indicam possíveis futuras capturas" (FERREIRA et al. 2004, p. 599).

Por outro lado, a carta de dissecação vertical, "tem como objetivo quantificar, em cada setor de cada sub-bacia hidrográfica, a altitude entre a linha de cumeada e o talvegue" (CUNHA, 2001, p. 50). Desse modo faz-se possível analisar o poder erosivo dos cursos fluviais, além de identificar e comparar os diferentes estágios erosivos presentes na área em estudo. 
Figura 1: Carta de localização da Bacia Hidrográfico do Córrego Moeda, Três Lagoas/MS

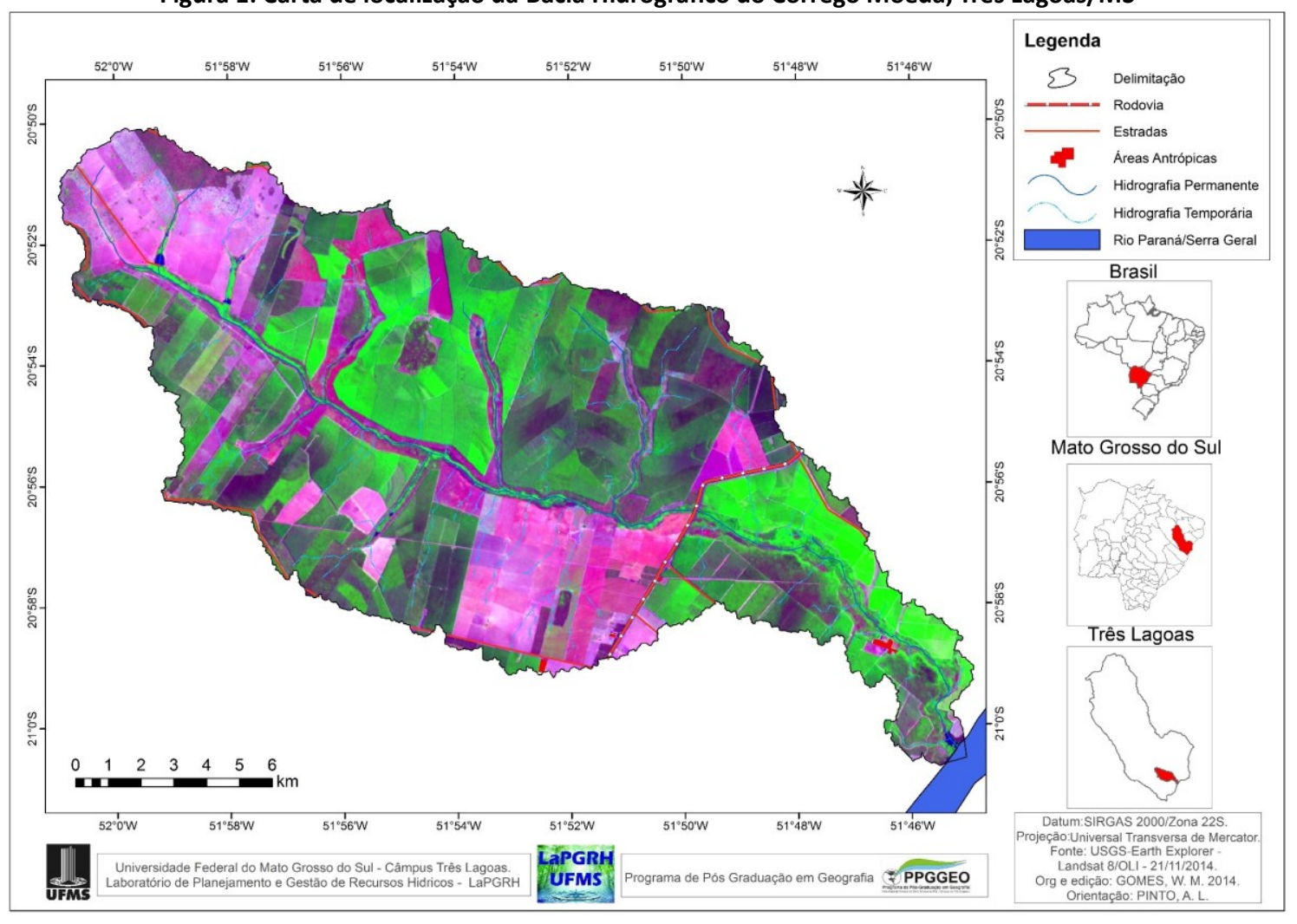

\section{OBJETIVOS}

O objetivo da pesquisa é analisar a dissecação horizontal e vertical levando em consideração os prolongamentos dos canais perenes, intermitente e efêmeros, de acordo com a metodologia de Spiridonov (1981), auxiliando, assim, por meio do comprimento e altitude das rampas, na compreensão da ação dos mananciais hídricos na compartimentação do relevo na Bacia Hidrográfica do Córrego Moeda, Três Lagoas/MS.

\section{METODOLOGIA}

\subsection{DISSECAÇÃO HORIZONTAL}

Para a elaboração da carta de Dissecação Horizontal foi adotada a proposta de Spiridonov (1981), considerando as adaptações de Mendes (1993) e Mauro et al. (1991).

Posteriormente fez-se necessário a delimitação das sub-bacias. Para isso foi utilizada a base cartográfica e as curvas de níveis obtidas por meio do modelo digital de elevação SRTM, e delimitando a área geográfica drenada por cada pequeno curso fluvial. Desse modo as áreas entre o talvegue e a linha de cumeada foram classificadas de acordo com a sua distância, por meio do ArcGis 10, sendo demarcadas as classes estabelecidas para a área em estudo.

A Figura 5 ilustra como foi elaborada a dissecação horizontal da BHCM. 


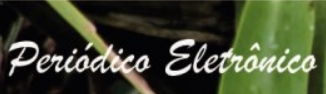

Figura 2: Metodologia de delimitação das sub-bacias, para a medição da distância e da elaboração das classes de Dissecação Horizontal, Grechia (2010).

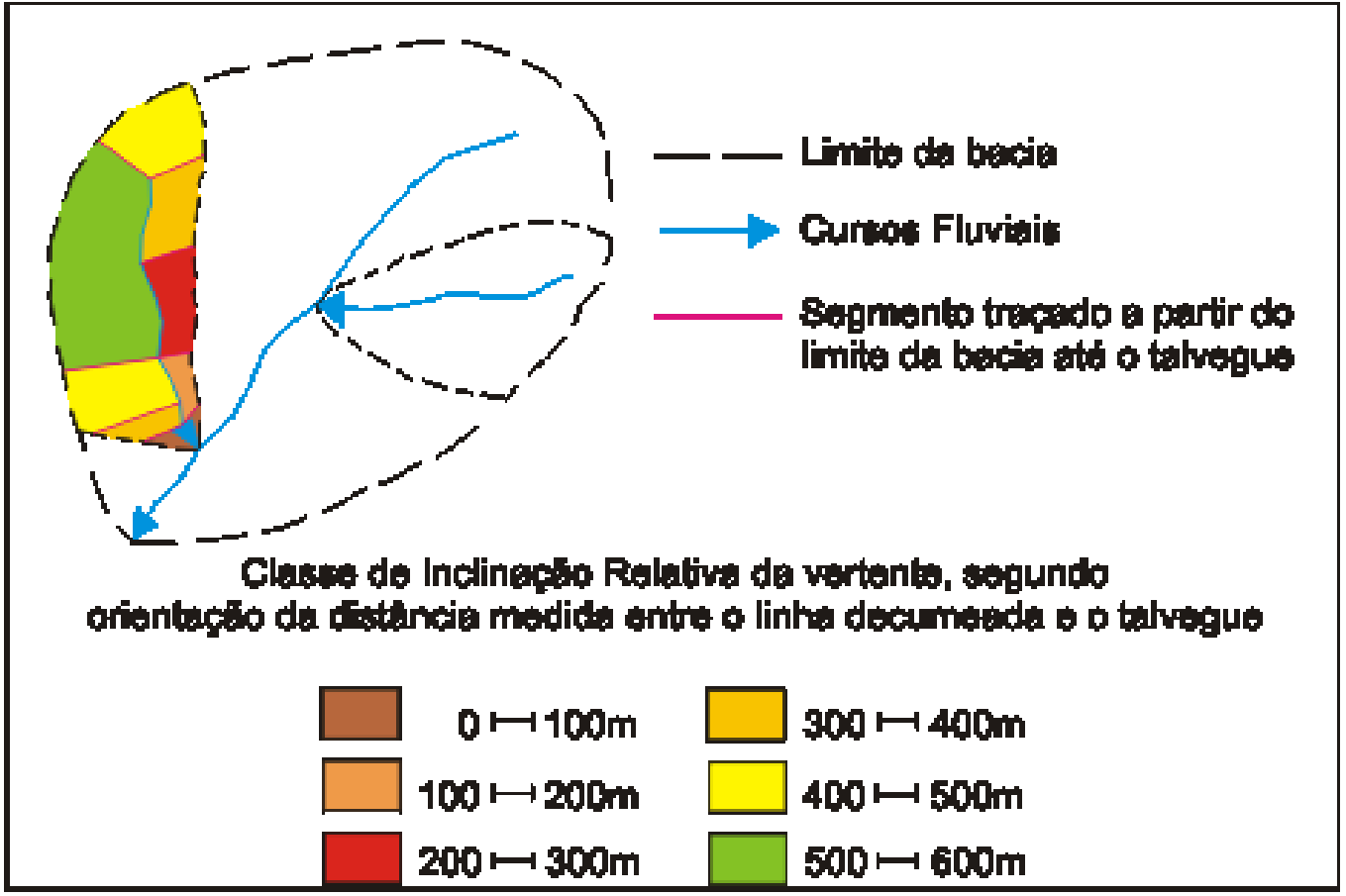

Fonte: Adaptação de Sato e Cunha (2007)

Para estabelecer as classes da carta de dissecação horizontal, foram consideradas as recomendações de Spiridonov (1981) com adaptações. Primeiramente foi identificada a máxima distância entre a linha de cumeada e o talvegue fluvial, com o objetivo de estabelecer a variação do referido parâmetro. O segundo passo é a elaboração das classes, utilizando-se uma adaptação, também, de Spiridonov (1981). Segundo o referido autor, deve-se dobrar os valores para criar os intervalos de classe, porém notou-se que a mesma iria generalizar a área de estudo. Logo, as classes foram alteradas de modo que se obteve, na carta, 10 classes que variam de 100 metros em 100 metros, uma classe de 500 metros e 1 classe que representa distâncias entre o talvegue e a linha de cumeada maior que 1500 metros. Essas classes representam o grau de dissecação no interior dos limites de cada sub-bacia do córrego Moeda.

\subsection{DISSECAÇÃO VERTICAL}

Para a elaboração da Dissecação Vertical foi utilizada a técnica proposta por Spiridonov (1981). Inicialmente, delimitou-se cada pequena sub-bacia. Em seguida, foram identificados os pontos onde ocorrem as intersecções entre os talvegues e cada curva de nível, sendo que esses pontos vão ser unidos às linhas de cumeada, passando a respeitar a linha de maior caída do relevo, ou seja, a menor distância entre o talvegue e a linha de cumeada, pois desse modo delimita-se setores dentro de cada sub-bacia, os quais serão classificados de acordo com sua altitude em relação ao talvegue. (OLIVEIRA, 2011) 


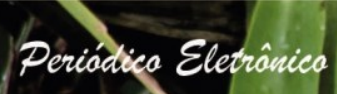

Para estabelecer as classes de Dissecação Vertical, também foi utilizada a proposta de Spiridonov (1981), que torna a equidistância entre as curvas de nível, que retrata o desnível altimétrico entre estas. As cores desta carta foram invertidas em relação às usadas para a Dissecação Horizontal, ou seja, as classes com menor altitude receberão cores suaves, e as classes com maiores altitudes cores fortes (OLIVEIRA, 2011).

Com a orientação da carta base e das delimitações de sub-bacias já estabelecidas pela carta de dissecação horizontal, foi utilizado o software ArcGis para definir as menores distâncias entre o ponto de interseção das curvas de nível com o talvegue.

A Figura 6 ilustra os procedimentos mencionados, e a Tabela 5 estabelece as classes de dissecação vertical da BHCM:

Figura 3: Metodologia para delimitação das sub-bacias, da medição da distância e da elaboração das classes da carta de Dissecação Vertical, Grechia (2010).

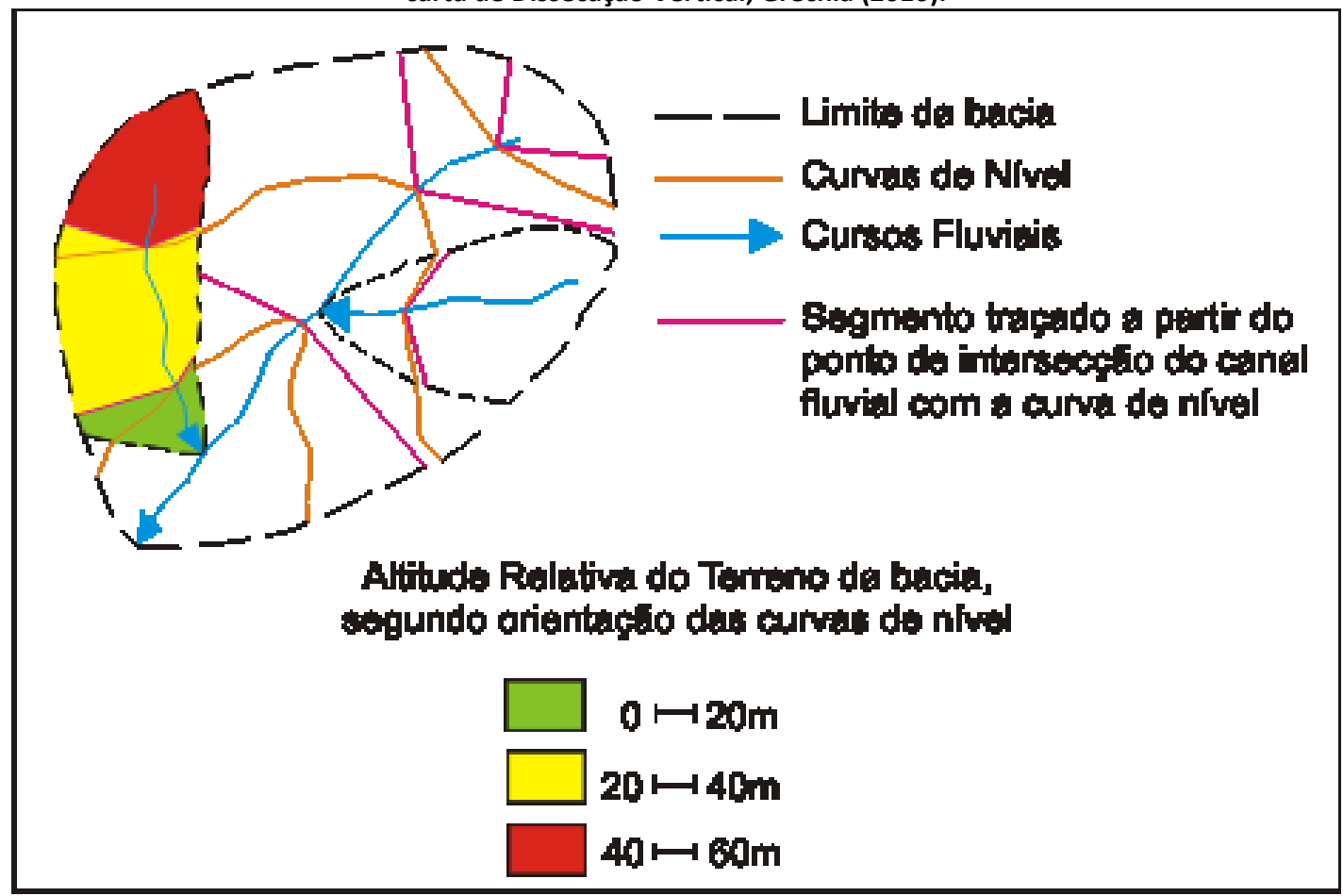

Fonte: Adaptação de Sato e Cunha (2007).

\section{RESULTADOS}

\subsection{DISSECAÇÃO HORIZONTAL}

A carta de dissecação horizontal faz com que seja possível quantificar a distância que separa os talvegues das linhas de cumeadas (CUNHA et al., 1976). Por meio dessa carta pode-se avaliar o trabalho de dissecação realizados pelos córregos e canais da BHCM. Logo, a carta de dissecação horizontal auxilia na avaliação da fragilidade potencial natural da bacia em relação à atuação dos processos morfométricos, indicando setores onde interflúvios mais estreitos indicam maior fragilidade e consequentemente, suscetibilidade à erosão. 
"A carta de dissecação horizontal auxilia na avaliação da fragilidade do terreno à atuação dos processos morfogenéticos, indicando setores onde interflúvios mais estreitos denotam maior suscetibilidade à atuação destes." (LEITE; ROSA, 2012, p. 271)

Observa-se grande quantidade de classes geradas a partir das diferenças entre as medidas do talvegue e a linha de cumeada, desse modo, foram estipuladas cores para a fácil distinção das classes. Logo, obteve-se na carta 10 classes que variam de 100 metros em 100 metros, uma classe de 500 metros e 1 classe que representa distâncias entre o talvegue e a linha de cumeada maior que 1500 metros. Essas classes representam o grau de dissecação no interior dos limites de cada sub-bacia do córrego Moeda.

As classes já mencionadas foram quantificadas de modo a observar a área ocupada por cada uma delas ficando, pois, como mostra a Tabela 1.

Tabela 1: Classes de Dissecação Horizontal com suas respectivas Áreas em $\mathrm{Km}^{2}$ e \% na Bacia Hidrográfica do Córrego Moeda, Três Lagoas/MS.

\begin{tabular}{llll}
\hline $\begin{array}{c}\text { Classes de Dissecação } \\
\text { Horizontal (metros) }\end{array}$ & Área (km²) & \multicolumn{1}{c}{ Área (\%) } & $\begin{array}{c}\text { Cores } \\
\text { Temáticas }\end{array}$ \\
\hline 0 a 100 & 23,26 & 9,36 & \\
100 a 200 & 46,76 & 18,88 & \\
200 a 300 & 43,04 & 17,38 & \\
300 a 400 & 32,15 & 12,98 & \\
400 a 500 & 27,36 & 11,05 & \\
500 a 600 & 21,35 & 8,62 & \\
600 a 700 & 16,1 & 6,50 & \\
700 a 800 & 12,72 & 5,14 & \\
800 a 900 & 6,5 & 2,62 & \\
900 a 1.000 & 5,53 & 2,23 & \\
1.000 a 1.500 & 11,45 & 4,62 & \\
$>1.500$ & 1,45 & 0,59 & \\
\hline Total & $\mathbf{2 4 7 , 6 7}$ & $\mathbf{1 0 0}$ & \\
\hline Org: Gomes (2015). & & &
\end{tabular}

Dentre as 12 classes de dissecação horizontal, a que apresenta maior risco potencial erosivo são as classes de 0 a 100 e 100 a 200m. Nessas classes os canais são curtos, mais retilíneos, logo o fluxo de água tende a ser mais veloz. A primeira abrange área de $23,26 \mathrm{~km}^{2}$ ou $9,36 \%$ e a segunda $46,76 \mathrm{~km}^{2}$ ou $18,36 \%$ da área total da bacia, logo as duas somam $70,02 \mathrm{~km}^{2}$ ou $28,24 \%$ da área da bacia. Desse modo parte considerável da bacia apresenta potencial erosivo significativo e devido a isso peso mais significativos.

A segunda classe em ordem de abrangência na BHCM é a de 200 a 300m que soma área de $43,04 \mathrm{~km}^{2}$ ou $17,38 \%$ da área da bacia.

As demais classes seguem em ordem decrescente em relação a área de abrangência de modo que a classe com menos potencial erosivo, que é a classe com dissecação maior que $1500 \mathrm{~m}$, abrange apenas área de $1,45 \mathrm{~km}^{2}$ ou $0,59 \%$ da bacia sendo, portanto, pouco expressiva. 


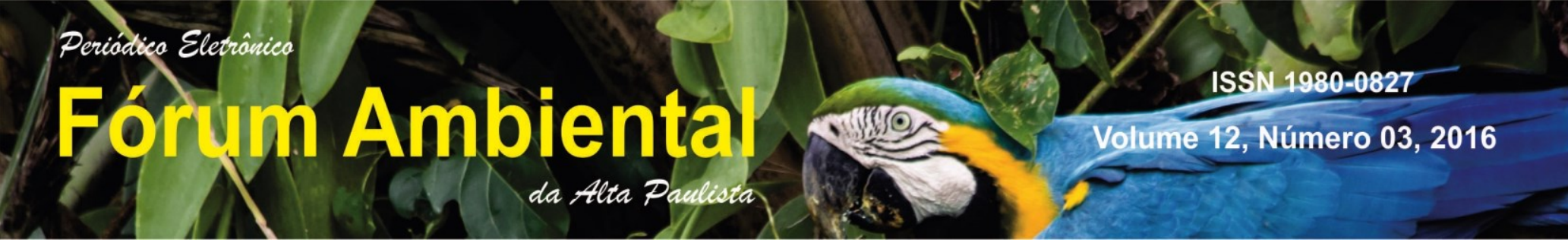

Figura 4: Rampas longas e baixa declividade com classe de dissecação Horizontal de 1000 a 1500.

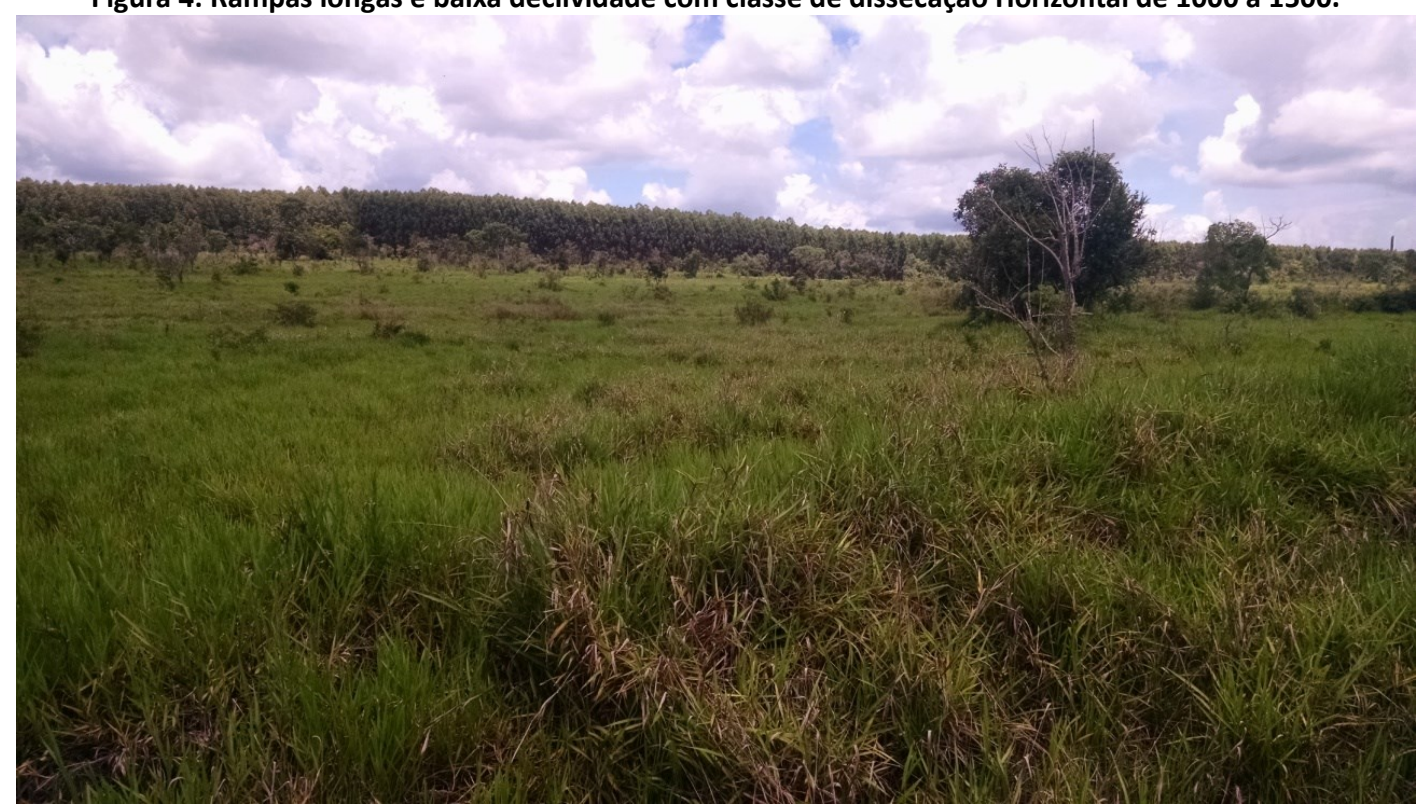

A Figura 4 exemplifica casos de rampas longas com declividade reduzida, próximo ao córrego buriti, cuja classe é 1000 a 1500 . Pouca declividade reduz a fragilidade ambiental mas as rampas alongadas elevam a fragilidade, pois o escoamento superficial vai se avolumando proporcionalmente ao comprimento da mesma, elevando a competência de carreamento de sedimentos na bacia.

Observou-se que as classes com fragilidade potencial natural mais forte são as que ocorrem nas confluências, até mesmo dos pequenos cursos fluviais e nas nascentes, (Figura 5) que se localizam demasiadamente próximas à linha de cumeada, visto que a proximidade entre os cursos fluviais implica em maior probabilidade de movimentação dos materiais constituintes do relevo, pela ação das águas correntes, conforme sua energia potencial do relevo. 


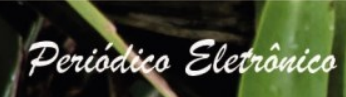 Forum Ambienta da rilta Paulista

Figura 5: Carta de Dissecação Horizontal da Bacia Hidrográfica do Córrego Moeda, Três Lagoas/MS

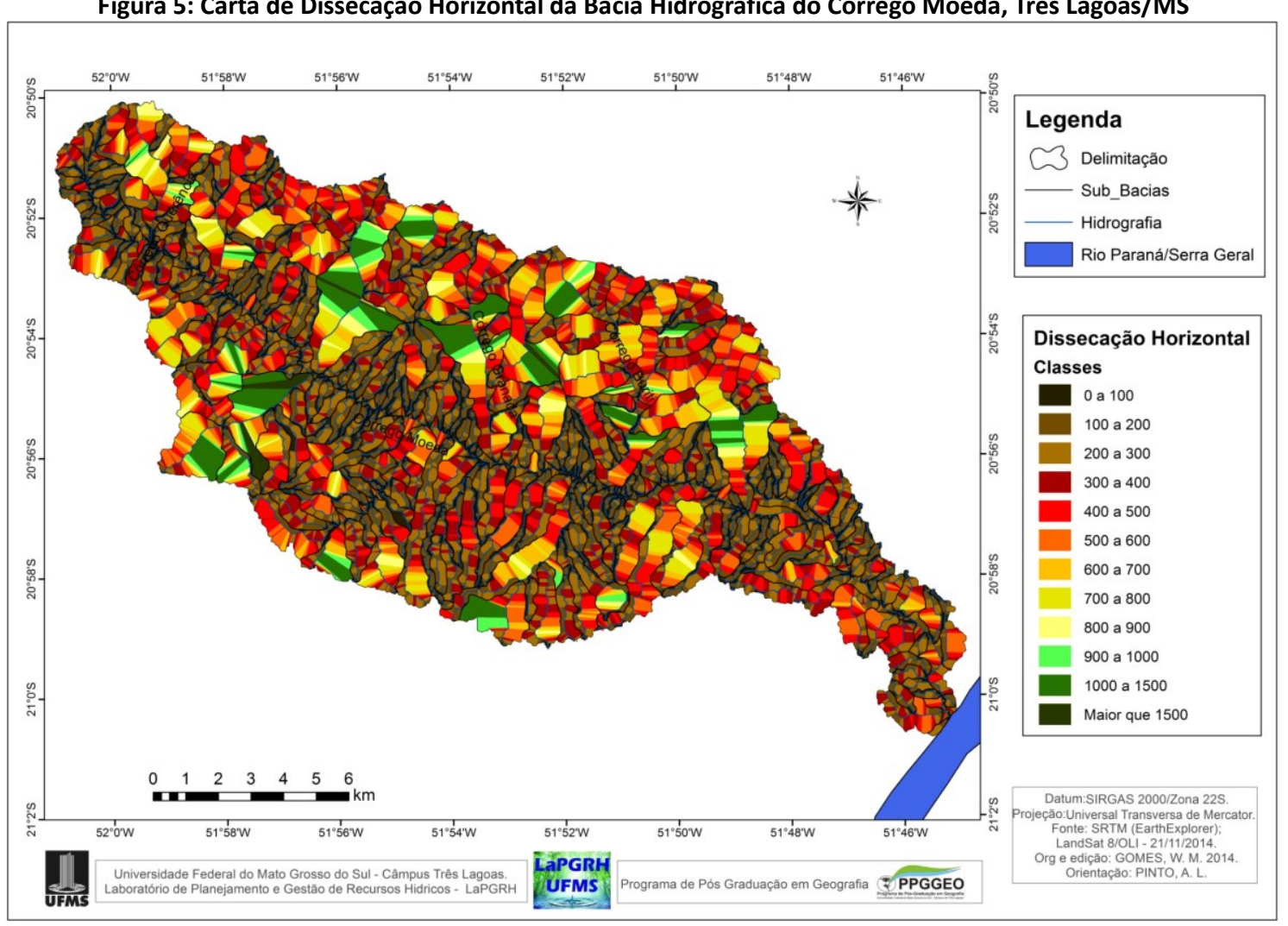

\subsection{DISSECAÇÃO VERTICAL}

A carta de dissecação vertical objetiva indicar áreas de potencial erosivo em relação às rupturas de nível do relevo das sub-bacias, que são indicadas por meio das curvas de nível da BHCM, indicando áreas com maior potencial de velocidade de fluxo d'água e consequentemente maior poder erosivo. (GRECHIA, 2011)

As áreas com maior risco de erosão, que se enquadram na classe de 100 a 110 e maior que $110 \mathrm{~m}$, se localizam, em sua maior parte no alto curso da BHCM, na nascente do Córrego Moeda, e no médio curso, nos limites da bacia, na margem direita. No entanto essas classes são pouco expressivas na bacia, uma vez que ocupam juntas, apenas $4,24 \mathrm{~km}^{2}$ ou $1,71 \% \mathrm{da}$ área total da bacia, Figura 6 e Tabela 2.

Nota-se, pelos dados da Tabela 2, extraídos da Figura 6, que a classe com maior quantitativo na BHCM é a de 10 a $20 \mathrm{~m}$, pois ocupa área de $47 \mathrm{~km}^{2}$ ou $19,24 \%$ da área total da bacia.

Em seguida nota-se representatividade na bacia as classes de 30 a $40 \mathrm{~m}$ e 20 a $30 \mathrm{~m}$ com área de ocorrência $46,00 \mathrm{~km}^{2}$ ou $18,57 \%$ e $40,15 \mathrm{~km}^{2}$ ou $16,21 \%$ respectivamente. 


\section{Periodtica Eletranica Forum Ambienta da Alta Paulista}

Tabela 2: Classes de Dissecação Vertical com suas respectivas Áreas em $\mathrm{Km}^{2} \mathrm{e} \%$. da Bacia Hidrográfica do Córrego Moeda, Três Lagoas/MS.

\begin{tabular}{llll}
\hline $\begin{array}{l}\text { Classes de Dissecação } \\
\text { Horizontal (metros) }\end{array}$ & Área $\left(\mathbf{k m}^{\mathbf{2}}\right)$ & Área (\%) & $\begin{array}{l}\text { Cores } \\
\text { Temáticas }\end{array}$ \\
\hline 0 a 10 & 25,62 & 10,34 & \\
10 a 20 & 47,65 & 19,24 & \\
20 a 30 & 40,15 & 16,21 & \\
30 a 40 & 46,00 & 18,57 & \\
40 a 50 & 32,13 & 12,94 & \\
50 a 60 & 21,03 & 8,49 & \\
60 a 70 & 15,34 & 6,19 & \\
70 a 80 & 7,57 & 3,06 & \\
80 a 90 & 4,30 & 1,74 & \\
90 a 100 & 3,73 & 1,51 & \\
100 a 110 & 1,98 & 0,80 & \\
$>110$ & 2,26 & 0,91 & \\
\hline Total & $\mathbf{2 4 7 , 6 7}$ & $\mathbf{1 0 0}$ & \\
\hline
\end{tabular}

Org: Gomes (2015).

Figura 6: Carta de Dissecação Vertical da Bacia Hidrográfica do Córrego Moeda, Três Lagoas/MS

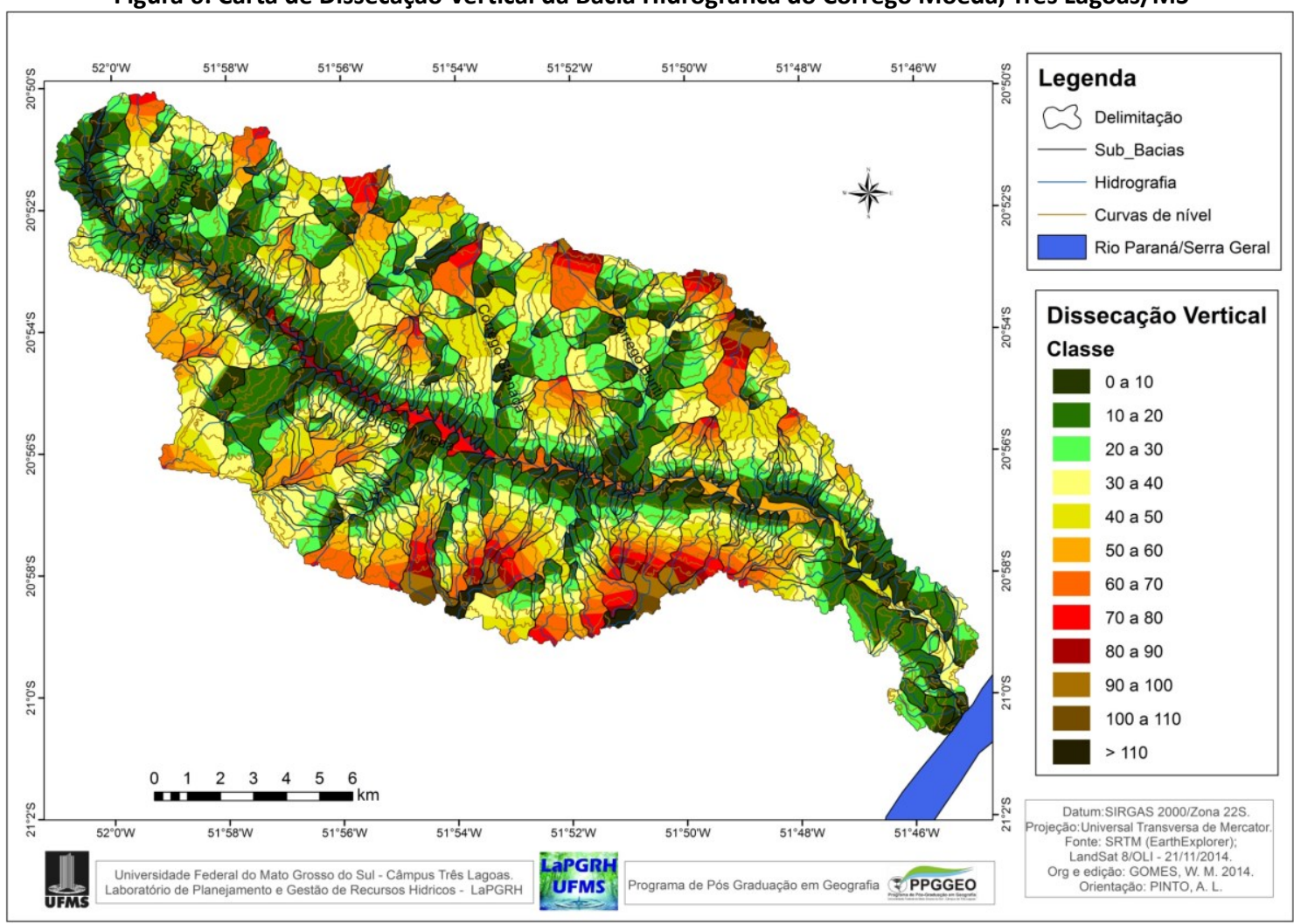




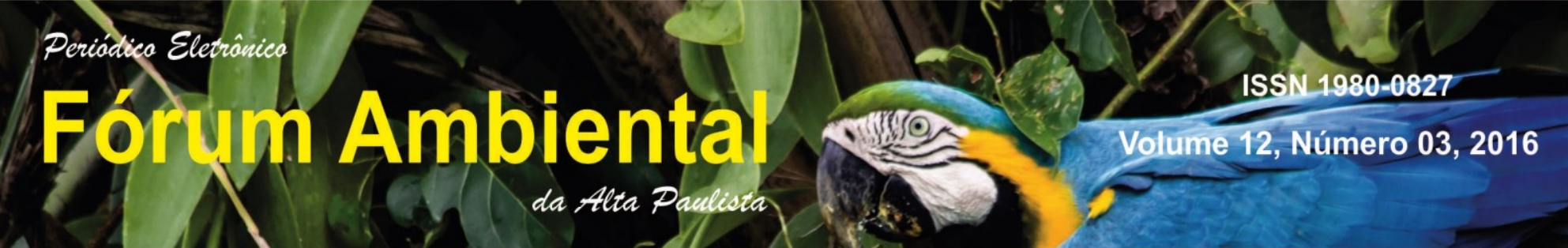

\section{CONCLUSÃO}

Esses processos erosivos, podem ser analisados de forma relativamente mais precisas com a elaboração das cartas de Dissecação Horizontal e Dissecação Vertical adaptadas da metodologia de Spiridonov (1981), visto que a delimitação das sub-bacias da BHCM e as alterações das classes de dissecações possibilitam integrar o escoamento superficial da pluviosidade e o potencial erosivo delas e não somente da dissecação dos córregos.

A utilização do ArcGis 10 para adaptação da metodologia de Spiridonov (1981) se mostrou eficaz para a classificação da dissecação horizontal e vertical dos terrenos na BHCM, agilizando o processo de criação e análise das cartas.

Dentre as 12 classes de dissecação horizontal, a que apresenta maior risco potencial erosivo são as classes de 0 a 100 e 100 a $200 \mathrm{~m}$, uma vez que nessas classes os canais são curtos, mais retilíneos, logo, o fluxo de água tende a ser mais veloz. A primeira abrange área de $23,26 \mathrm{~km}^{2}$ ou $9,36 \%$ e a segunda $46,76 \mathrm{~km}^{2}$ ou $18,36 \%$ da área total da bacia, somam juntas $70,02 \mathrm{~km}^{2}$ ou $28,24 \%$ da área da bacia.

Em relação a dissecação vertical da $\mathrm{BHCM}$, as áreas com maior risco de erosão, que se enquadram na classe de 100 a 110 e maior que $110 \mathrm{~m}$, se localizam, em sua maior parte no alto curso da BHCM, na nascente do Córrego Moeda, e no médio curso, nos limites da bacia, na margem direita.

Desse modo parte considerável da bacia apresenta potencial erosivo significativo, necessitando de cuidados e manejo adequado, bem como a preservação da vegetação nessas referidas áreas, a qual possibilita a diminuição da velocidade do fluxo de agua e cujas raízes agregam o solo e contribuem para que a quantidade de sedimentos carreados para os córregos e o surgimento de sulcos e ravinas sejam minimizados.

\section{REFERENCIAS}

BOTELHO, R.G.M.; SILVA, A. S. Bacia Hidrográfica e Qualidade Ambiental. In: Reflexões sobre a Geografia Física no Brasil. 1.ed. Rio de Janeiro: Bertrand Brasil, 2004. p.153-157

CUNHA, C. M. L. A cartografia do relevo no contexto da gestão ambiental. Tese (Doutorado). Universidade Estadual Paulista; Instituto de Geociências e Ciências e Exatas. Rio Claro, 2001.

CUNHA, C. M. L; MENDES, L A; SANCHES, M. C. Técnicas de elaboração, possibilidade e restrições de cartas morfométricas na gestão Ambiental. GEOGRAFIA, Associação de Geografia Teorética. V.1 (1976) - Rio Claro, SP: AGETEO, 1976

FERREIRA, M. V.; TINOS, T. M.; PINTON, L. G.; CUNHA, C. M. L. Dissecação horizontal como parâmetro morfométrico para avaliação do relevo: proposta de técnica digital automática. Revista Brasileira de Geomorfologia, v. 15, p. 585600, 2014.

GRECHIA, L. Dinâmica geomorfológica da bacia hidrográfica do córrego bom jardim, Brasilândia/MS. 2011. 133p. Dissertação (Mestrado) - Universidade Federal de Mato Grosso do Sul - UFMS. Três Lagoas/MS 29/04/2011.

LEITE, E. F.; ROSA, R. Mapeamento Geomorfológico: A Carta de Energia do Relevo da Bacia Hidrográfica do Rio Formiga-TO. Revista Brasileira de Geografia Física, v. 02, p. 269-284, 2012.

MAURO, C. A. et al. Contribuição ao planejamento ambiental de Cosmópolis - SP - BR. In: Encuentro de geógrofos de América Latina, 3, 1991. Toluca. Memórias. Toluca: UAEM, v, 4, 1991, p $391-419$.

MENDES, I. A. A dinâmica erosiva do escoamento pluvial na bacia do Córrego Lafon - Araçatuba / SP. 1993. 171 f.: Tese (Doutorado) - Faculdade de Filosofia, Letras e Ciências Humanas, USP, São Paulo. 


\section{Periadica Eletrónica

Oliveira, g. h. A erosividade da bacia hidrográfica do córrego Bom Jardim, Brasilândia/MS. UFMS, Campus de Três Lagoas, 2011, 85p. (Monografia de Graduação em Bacharelado em Geografia).

SPIRIDONOV, A. I. Princípios de la metodologia de las investigaciones de campo y El mapeo geomorfológico. Havana: Universidad de la Havana, Faculdad de Geografia, 1981. 3v. 